Universidad de Guadalajara

Derecho Global. Estudios sobre Derecho y Justicia Año 2021, Vol. VI. Número 17, Marzo - Junio, pp 77-106, ISSN: 2448-5128 e-ISSN: 2448-5136

https://DOI.org/10.32870/dgedj.v6i17.356

GEORGINA DORONI

Universidad Nacional de Córdoba, Argentina georginadoroni@gmail.com

\title{
COSTOS AMBIENTALES-SOCIALES EN EL MARCO DE LA MERCANTILIZACIÓN DE LOS RECURSOS naturales. Contextos de Vulnerabilidad SOCIAL-AMBIENTAL
}

\section{ENVIRONMENTAL-SOCIAL COSTS IN THE FRAMEWORK OF THE COMMODIFICATION OF NATURAL RESOURCES. CONTEXTS OF SOCIAL- ENVIRONMENTAL VULNERABILITY}

Recibido: 12/05/2020 Aceptado: 10/11/2020 


\section{RESUMEN}

En el contexto del neo-extractivismo en América Latina (específicamente en Argentina) se pretende abordar los "daños colaterales" que encierran los proyectos de desarrollo y progreso económico sobre las variables socio-ambientales. A través de un análisis de tipo descriptivo y relacional se abordarán los costos ambientales-sociales que dicho accionar genera, acrecentados en sujetos que se encuentran en situaciones de vulnerabilidad -comunidades locales que se ven desplazadas y afectadas por el desarrollo de proyectos económicos-. Esta situación genera una deuda social-ecológica (pasivos ambientales y sociales) que requiere de medidas para la remediación y compensación de dicha deuda y arbitrar mecanismos legales de preservación y prevención de los derechos ambientales.

En función de lo expuesto, el presente trabajo se propone: a) explicitar la relación entre el medio ambiente y los derechos humanos, para luego b) enmarcar la problemática de los costos ambientales-sociales generados por una práctica de mercantilización de los recursos naturales; c) evidenciando la relación entre dichos costos y contextos de vulnerabilidad socio-ambiental; d) abordar medidas de remediación y compensación de la deuda socialecológica generada y medidas prevención de los derechos ambientales.

\section{Palabras Clave:}

mercantilización - costos ambientales y sociales-vulnerabilidad social-ambiental-pasivos ambientales.

\section{Abstract}

In the context of neo-extractivism in Latin America (specifically in Argentina), the aim is to address the "collateral damage" that development and economic progress projects have on socioenvironmental variables. Through a descriptive and relational analysis, the environmentalsocial costs that such action generates will be addressed, increased in subjects who are in situations of vulnerability -local communities that are displaced and affected by the development of economic projects-. This situation generates a social-ecological debt (environmental and social liabilities) that requires measures for the remediation and compensation of said debt and arbitrating legal mechanisms for the preservation and prevention of environmental rights. 
Based on the foregoing, this paper aims to: a) explain the relationship between the environment and human rights, and then b) frame the problem of environmental-social costs generated by a practice of commodification of natural resources; c) evidencing the relationship between these costs and contexts of socio-environmental vulnerability; d) Address measures of remediation and compensation of the generated social-ecological debt and measures to prevent environmental rights.

\section{KEY WORDS:}

Commodification - Environmental-social costs- social-environmental vulnerabilityenvironmental liabilities.

Sumario: I. Derechos humanos y medio ambiente. II. La nUeva Cara DE LA COLONIALIDAD: MERCANTILIZACIÓN DE LOS RECURSOS AMbientales. III. Derecho al ambIente SANO COMO DISCURSO PROMOTOREINSTRUMENTOPARALADEFENSA DELOS DERECHOS HUMANOS. IV. LA OTRA CARA DE LA COLONIALIDAD: COSTOS (PASIVOS) SOCIALESAMBIENTALES. V. InStancias DE PARTICIPACIÓN SOCIAL. VI. Conclusiones. Bibliografía.

\section{Derechos humanos Y Medio AMBIENTE ${ }^{1}$}

1 establecerse la relación entre los derechos humanos y el medio ambiente,
manera instrumentos de derechos humanos y ambientales contribuyen de
ambiente saludable ${ }^{2}$. Sin embargo, en la actualidad se observa una gran distancia
entre las proclamaciones y consagraciones jurídicas-normativas y el plano de la

${ }^{1}$ Dicho análisis se efectúo con mayor profundidad en el artículo de propia autoría "Pasivos ambientales en el contexto del derecho humano al ambiente sano. La exigencia de remediación de los PA: participación ciudadana y contextos de desigualdad socio-ambiental", en "Cuaderno de Derecho Ambiental $N^{\circ} \mathrm{X}$ - Derechos Ambiental y Derechos Humanos”, Año 2018, IJ Editores, págs. 82-100.

2 Naciones Unidas: Asamblea General (2011): Estudio analítico de la relación entre los derechos humanos y el medio ambiente. Informe de la Alta Comisionada de las Naciones Unidas para los Derechos Humanos, A/ HRC/19/34, 16 de diciembre de 2011, párr.24. 
eficacia y efectividad de los derechos consagrados ${ }^{3}$; por lo que si bien contamos con una "faz estructural" de amplio reconocimiento legislativo de los derechos ${ }^{4}$, no logramos avanzar en la implementación.

Los derechos humanos están interrelacionados: el ambiente desempeña una función esencial en la protección y la promoción de los derechos humanos y a su vez el lenguaje de los derechos humanos es el campo propicio y fértil para expresar los reclamos medioambientales (v.gr. calidad de vida, salubridad, igualdad socioambiental, ambiente sano). Sin embargo, el propio término "derecho humano" es reduccionista, dado que desconoce la dimensión colectiva que abarca la propia configuración del derecho al medio ambiente y la función ecológica-ambiental propiamente dicha (valores intrínsecos del medio ambiente).

(...) Específicamente nos referimos al derecho humano al ambiente sano: ¿cómo reducir el considerable abismo que sigue existiendo entre el discurso y las normas de derechos humanos y la injusta realidad que viven millones de seres humanos?"5, ¿es acaso el derecho humano al ambiente sano el derecho de unos pocos? Sin adelantarnos al meollo del análisis, una primera respuesta intuitiva es que de poco sirve consagrar un derecho igualitario al ambiente sano si paralelamente no contamos con los mecanismos preventivos y correctivos para la internalización de los costos socio-ambientales que genera una determinada actividad, proyecto y determinados sectores soportan las cargas y costos de la contaminación. "Existe una distancia entre lo que las normas declaran y el efecto que producen ${ }^{6}$.

Se puede entrever el componente social que subyace en el fondo del análisis: la desigualdad socio-ambiental que sufren ciertos sectores soportando la existencia de sitios contaminados; y por otro, el componente ambiental (ecológico): la idea

\footnotetext{
${ }^{3}$ Uno de los factores que tal vez contribuyen a que no se progrese tanto como es deseable en la promoción de los derechos del hombre es la creencia de que ella está asegurada cuando se alcanza un reconocimiento jurídico de los derechos en cuestión. NINO, Carlos S (2012). Ética y derechos humanos, Astrea, Buenos Aires, pág. 3.

${ }^{4}$ Los indicadores estructurales buscan medir qué medidas dispone el Estado para implementar los derechos del Protocolo. Ver Organización de los Estados Americanos, Comisión Interamericana de Derechos Humanos (2012), "Lineamientos para la elaboración de indicadores de progreso en materia de derechos económicos, sociales y culturales", pág. 17.

${ }^{5}$ Arbour, Louise. Plan de acción presentado por la Alta Comisionada de las Naciones Unidas para los Derechos Humanos, A/59/2005/Add.3, 2006-2007.

${ }^{6}$ Lorenzetti, Ricardo L (2007). "La protección jurídica del ambiente”, en La Ley 1997-E, 1463 - Responsabilidad Civil Doctrinas Esenciales Tomo V, 01/01/2007, 1497.
} 
de un "derecho humano al ambiente sano" no deja de ser reduccionista a un único modelo de desarrollo y epistemología que solo reconoce el derecho al ambiente sano en función de las necesidades y parámetros de los seres humanos ${ }^{7}$.

Partiendo de la consideración de que los derechos humanos son universales, indivisibles e interdependientes y están relacionados entre $\mathrm{si}^{8}$, se categoriza al derecho al medio ambiente sano como un derecho humano básico y esencial, en tanto su ejercicio apareja a su vez el goce y disfrute de los restantes derechos de los individuos. "Existe una relación innegable entre la protección del medio ambiente y la realización de otros derechos humanos"910.

Más allá de la interdependencia teórica o retórica, esta relación se torna virtuosa cuando los reclamos medioambientales encuentran asidero en el plano de los derechos humanos, cuando los derechos se materializan en el ejercicio de acciones, reclamos que se promueven en defensa del medio ambiente, acciones de prevención y remediación de daños ambientales.

El reconocimiento de la estrecha relación que existe entre los derechos humanos y el medio ambiente ha adoptado principalmente dos formas ${ }^{11}$ : a) la

\footnotetext{
${ }^{7}$ Reflejado explícitamente en el principio 1 de la Declaración de Rio sobre el Medio Ambiente y el Desarrollo: "Los seres humanos constituyen el centro de las preocupaciones relacionadas con el desarrollo sostenible. Tienen derecho a una vida saludable y productiva en armonía con la naturaleza".

${ }^{8}$ Consejo de Derechos Humanos, A/HRC/RES/34/20, 6 de abril de 2017.

${ }^{9}$ CORTE IDH: Caso Kawas Fernández vs. Honduras, sentencia de 3 de abril de 2009 (Fondo, Reparaciones y Costas), párr.148: El derecho a un ambiente sano es una "condición" para el goce de otros derechos: varios derechos de rango fundamental requieren, como una precondición necesaria para su ejercicio, una calidad ambiental mínima, y se ven afectados en forma profunda por la degradación de los recursos naturales. En idéntico sentido CIDH, Informe N ${ }^{\circ} 125 / 12$, Pueblos indígenas Kuna de Madungandí y Emberá de Bayano y sus miembros vs. Panamá, 30 de noviembre de 2012, párr. 233.

${ }^{10}$ Afirmado también por las Naciones Unidas, al adoptar la Agenda 2030 para el Desarrollo Sostenible la Asamblea General reconoció que el alcance de los derechos humanos de todas las personas depende de la consecución de las tres dimensiones del desarrollo sostenible: la económica, social y ambiental. Cfr. Asamblea General de las Naciones Unidas, Resolución 70/1, titulada "Transformar nuestro mundo: la Agenda 2030 para el Desarrollo Sostenible”, 25 de septiembre de 2015, Doc. ONU A/RES/70/1, preámbulo y párrs. 3, 8, 9, 10, 33,35 y 67.

${ }^{11}$ En igual sentido ha sido reconocido por la Corte IDH, lo que implica un salto cualitativo en el reconocimiento de la faz colectiva del derecho al medio sano: "El derecho humano a un medio ambiente sano se ha entendido como un derecho con connotaciones tanto individuales como colectivas. En su dimensión colectiva, el derecho a un medio ambiente sano constituye un interés universal, que se debe tanto a las generaciones presentes y futuras. Ahora bien, el derecho al medio ambiente sano también tiene una dimensión individual, en la medida en que su vulneración puede tener repercusiones directas o indirectas sobre las personas debido a su conexidad
} 
adopción de un nuevo derecho explícito al medio ambiente, caracterizado como saludable, sin riesgos, satisfactorio o sostenible; y b) una mayor atención a los vínculos con el medio ambiente de derechos ya reconocidos, como los derechos a la vida y a la salud ${ }^{12}$. Incluso, las situaciones de contaminación ambiental se tornan incompatibles con el derecho a ser respetado como ser humano (dignidad humana $)^{13}$.

Conforme lo desarrollado, se formulan las siguientes apreciaciones:

a) El medio ambiente se considera como un bien jurídico de protección, prevención, recomposición y/o remediación, sí y solo sí se afecta de manera (directa o indirecta) otros derechos humanos, en tanto el disfrute de otros derechos humanos se vean afectados por una degradación de las condiciones medioambientales.

La propia redacción del art. 41 de la $\mathrm{CN}$ en su parte pertinente dice:

Todos los habitantes gozan del derecho a un ambiente sano, equilibrado, apto para el desarrollo humano (...).

Correlativamente Gudynas manifiesta que: “(...) casi todas estas manifestaciones regresan y se basan en las valoraciones y utilidades humanas. Un aspecto clave en estas posturas es su visión dualista, donde el ser humano se separa y es distinto de la naturaleza, y en tanto es medida, origen y destino de todos los valores, se apropia de los recursos naturales al entenderlos únicamente como medios para nutrir los procesos productivos contemporáneos. En síntesis,

\footnotetext{
con otros derechos, tales como el derecho a la salud, la integridad personal o la vida, entre otros" (Corte IDH, Opinión Consultiva OC-23/17, párrf.59, de 15 de noviembre de 2017, solicitada por la República de ColombiaMedio ambiente y derechos humanos).

${ }^{12}$ Naciones Unidas: Asamblea General: Informe del Experto independiente sobre la cuestión de las obligaciones de derechos humanos relacionadas con el disfrute de un medio ambiente sin riesgos, limpio, saludable y sostenible, John H. Knox, A/HRC/22/43, 24 de diciembre de 2012, párr.10-11.

${ }^{13}$ Ver Comisión Interamericana de Derechos Humanos. Informe sobre la Situación de los Derechos Humanos en Ecuador, OEA/SerieL/V/II.96, doc. 10 rev. 1, 24 de abril de 1997, párr.92.
} 
la localización epistémica de la valoración siempre es humana"14. "El mundo que surge como resultado de esta razón pragmática es aquel en donde todo sirve para algo, y tiene que ser útil para ser reconocido como real [...] Es esta racionalidad instrumental la que pone de manifiesto el proceso de alienación social y socioecológico de la sociedad moderna"15.

b) Es esta "racionalidad instrumental la que pone de manifiesto el proceso de alienación social y socio-ecológico de la sociedad moderna"1617 lo que invita a replantearnos que la adopción de un nuevo derecho explícito al medio ambiente nos permite analizar la convergencia del medio ambiente y los derechos humanos desde las siguientes perspectivas:

a) por un lado, se traduce en la expresión clásica e individualista del derecho a un ambiente sano como derecho humano natural e individual, ínsito a la condición de ser humano y vinculada con el disfrute de otros derechos humanos (protección vía indirecta); b) por otro lado, implica un derecho de dimensión social (emplazamiento social del derecho) y colectiva (la defensa de los derechos humanos responde a un interés público y en este caso con vocación colectiva) ${ }^{18}$, c) y bajo esta misma lógica debiera traducirse y

\footnotetext{
${ }^{14}$ Gudynas, Eduardo (2010). "La senda biocéntrica: valores intrínsecos, derechos de la naturaleza y justicia ecológica”, en Tabula Rasa. Bogotá - Colombia, No.13, julio-diciembre 2010, ISSN 1794-2489, pág. 49.

${ }^{15}$ Galafassi, Guido P. (2004). "Razón instrumental, dominación de la naturaleza y modernidad: la Teoría Crítica de Max Horkheimer y Theodor Adorno" en Revista Theomai, nº, primer semestre, pág. 101 [en línea] http:// revista-theomai.unq.edu.ar/numero9/artgalafassi\%28frankf\%299.htm [consulta: 5 de julio de 2019].

${ }^{16}$ Ibídem, pág. 101.

${ }^{17} \mathrm{Si}$ todo conocimiento es para dominar, de la fórmula que saber es poder, la razón que impulsa el conocimiento no es más que un instrumento al servicio de la dominación. La razón como exclusividad fue sinónimo de dominio. Si nuestra condición humana nos data de una mayor capacidad para idear instrumentos y herramientas (tecnología) cabe pensar que no lo hace para que nos destruyamos mejor entre nosotros y hagamos lo mismo con los otros entes hasta aniquilar las condiciones de nuestra habitabilidad en el planeta. El humano es el señor absoluto de la naturaleza y su misión progresista y racional consiste en dominarla. (ZAFFARONI, Eugenio Raúl (2012). La Pachamama y el Humano. Buenos Aires: Madres de Plazas de Mayo, Ediciones Colihue, pág.35.

${ }^{18}$ Cfr. Morales Lamberti, Alicia (2015). "Los derechos humanos en el Código Civil y Comercial, como fuentes de integración hermenéutica y reconocimiento axiológico en la aplicación del derecho ambiental”, en Revista de Derecho Ambiental № 43, AbeledoPerrot, Junio-Septiembre 2015, págs. 139-164.
} 
emplazarse el derecho en una dimensión ecológica, reconociendo la existencia del derecho a la reparación del medio ambiente per $\mathrm{se}^{19}$. Esto último implica reconocer nuevas dimensiones de valor ${ }^{20} \mathrm{y}$ admitir el derecho a la regeneración de su biocapacidad y continuación de sus ciclos y procesos vitales libres de alteraciones humanas; el derecho a estar libre de contaminación, polución y desechos tóxicos o radioactivos; el derecho a no ser alterada genéticamente y modificada en su estructura amenazando su integridad o funcionamiento vital y saludable; el derecho a una restauración plena y pronta ${ }^{21}$.

\section{La CIDH ha manifestado: "Se trata de proteger la naturaleza y el medio ambiente no solamente por su conexidad con una utilidad para el ser humano o por los efectos que su degradación podría causar en otros derechos de las personas, sino por su importancia para los demás organismos vivos con quienes se comparte el planeta, también merecedores de protección en sí mismos"22.}

\footnotetext{
${ }^{19}$ En palabras de Gudynas: "Uno de los frentes de análisis y debates más activos en el amplio campo del ambiente y el desarrollo se ha enfocado en el reconocimiento de valores intrínsecos en la Naturaleza, donde ésta pasa a ser sujeto de derechos. Como la postura tradicional ha sido entender al ambiente como objeto al servicio del ser humano, ese reconocimiento conlleva rupturas en varios terrenos, involucrando novedades como el reconocimiento de derechos propios de la Naturaleza (...)"(Gudynas, Eduardo (2010). "La senda biocéntrica: valores intrínsecos, derechos de la naturaleza y justicia ecológica", en Tabula Rasa. Bogotá - Colombia, No.13: 45-71, julio-diciembre 2010, pág. 47.

${ }^{20}$ Es importante advertir que el reconocimiento de los valores intrínsecos, no niega ni altera los contenidos referidos a los derechos ciudadanos a un ambiente sano. Los dos abordajes de derechos sobre el ambiente son válidos, y es una buena cosa que se los mantuviera y se los articulara entre sí. Tan sólo es necesario tener presente que estos derechos clásicos a un ambiente sano tienen su foco en las personas: son derechos humanos, donde se cuida de la Naturaleza en tanto esto puede afectar a las personas, y no por los valores propios de ésta (Gudynas, Eduardo. "Los derechos de la Naturaleza en serio. Respuestas y aportes desde la ecología Política" (2011). En La naturaleza con derechos. De la filosofía política. Abya Yala y Universidad Politécnica Salesiana. Quito, Ecuador, pág. 253.

${ }^{21}$ Proyecto de Declaración Universal de los Derechos de la Madre Tierra (2010).

${ }^{22}$ Corte IDH, Opinión Consultiva OC-23/17, párrf.62, de 15 de noviembre de 2017, solicitada por la República de Colombia- Medio ambiente y derechos humanos.
} 


\section{LA NUEVA CARA DE LA COLONIALIDAD: MERCANTILIZA- CIÓN DE LOS RECURSOS AMBIENTALES}

El deterioro ambiental y socio-cultural es el resultado de un proceso en el que han prevalecido los intereses económicos sobre las consideraciones ambientales. Lo que en un primer momento fue en busca de un progreso, mejor calidad de vida, satisfacer necesidades básicas, inclusión en el mercado-mundo (global) se combinó con acciones "depredatorias" e irresponsables respecto al "uso y abuso" de los recursos naturales. "Históricamente, la explotación y sobreexplotación de la naturaleza ordenaron las relaciones entre la economía y la sociedad, lo que configuró un cuadro de desigualdad estructural y variadas formas de exclusión"23, incluso es la moneda corriente con la que se deben enfrentar comunidades locales frente a la imposición y expansión de proyectos de desarrollo y progreso económico.

El problema que subyace ante la práctica continua de mercantilización de nuestros recursos naturales es la justificación de que esa es la única vía de inserción y avance de los países en vías de desarrollo ${ }^{24}$, lo que hace que "los gobiernos de distinto signo, a un lado y otro del arco político, siguen apostando a la sobreexplotación de la naturaleza como forma de insertarse en una economía cada vez más globalizada y financiarizada"25. Estas prácticas de subordinación generan territorios vaciables, recursos apropiables, comunidades desplazadas,

\footnotetext{
${ }^{23}$ Fundación ambiente y recursos naturales (2019). Pulso ambiental. Revista política y de debate $\mathrm{N}^{\circ} 12$, septiembre 2019, pág. 4.

${ }^{24}$ En ese sentido, "Se podría afirmar, desde una perspectiva socio-ambiental, que el carácter de la globalización, o por lo menos la difusión de la ideología neoconservadora que sostiene la modernidad hegemónica en estos días, sólo les deja a nuestras sociedades optar por dos caminos alternativos. O bien se integran, en forma subordinada y dependiente, al mercado-mundo, o no les quedará otra que la ilusión de la autonomía, pero con la realidad del atraso. Sin embargo, el verdadero problema que se debe debatir no es la obvia existencia de tendencias hacia la inserción en la economía globalizada, sino qué tipo de inserción nos conviene, qué tipo de inserción permite tomar las riendas del crecimiento en bases nacionales y qué tipo de inserción permite mantener la identidad cultural, la cohesión social y la integridad ambiental en nuestros países". GUIMARÃES, Roberto P (1998). "La ética de la sustentabilidad y la formulación de políticas de desarrollo", en Ambiente \& Sociedades, No. 2, págs. 53-82.

${ }^{25}$ Ibídem, pág. 4.
} 
daños socio-ambientales, que se tratan de mostrar como "daños colaterales del progreso". "La extracción de recursos naturales no sólo tiene impactos sociales y ambientales, además se lleva a cabo con violación de derechos humanos o de la naturaleza" 26 . Ese colonialismo, que se arrastra desde el origen mismo de nuestra historia latinoamericana (y argentina) encuentra hoy un nuevo ropaje: la mercantilización de nuestros recursos naturales y territorios ricos en biodiversidad. Bajo la noción y dicotomía de "progreso-barbarie" se justifica y perpetúa la "dominación": "Debemos mantener las puertas bien abiertas a la inversión extranjera (...) porque necesitamos más de lo que podemos obtener (...) En América Latina es lo normal: siempre se entregan los recursos en nombre de la falta de recursos" ${ }^{27}$.

Nueva colonización representada por contratos de inversión sin atención $u$ ocultamiento de normativas protectorias, que reducen los costos transaccionales (laborales, sociales, ambientales, fiscales). Contratos de inversión totalmente disímiles si donde se ejecutan son en países desarrollados, en cuyo caso incluyen cláusulas de protección al ambiente, de la salud, restauración de las áreas, comisiones de participación ciudadana. Gestionamos nuestros recursos conforme parámetros, estándares y necesidades de las grandes empresas y países del norte, favoreciendo y siendo "cómplices" del proceso de mercantilización de los recursos.

a) Casos recientes en nuestro país: Esa "vocación rentista" 28 que caracteriza a los países latinoamericanos permite la banalización de nuestros recursos bajo los sagrados mandatos de libertad de comercio, atracción y libertad de capitales, ausencia de barreras y medidas de protección. Situación que condice a extremos, caso que evidenciamos en Argentina de colocar los recursos naturales como garantía de la deuda que nuestro país contrajo, como garantía de cobro y ejecución

\footnotetext{
${ }^{26}$ Gudynas, Eduardo (2013), "Extracciones, extractivismos y extraheccione. Un marco conceptual sobre la apropiación de recursos naturales", Observatorio del Desarrollo, No 18, Febrero 2013.

${ }^{27}$ Galeano, Eduardo (2013). Las venas abiertas de América Latina, Buenos Aires: Siglo XXI Editores, pág. 180. ${ }^{28}$ Ibídem, pág. 287
} 
de la deuda nacional asumida por la Nación ${ }^{29}$. Decretos que modifican el régimen de protección de bienes ante posibles demandas judiciales por incumplimientos de pago, dado que si bien explicitan las excepciones a dicha garantía (art. 1 del Decreto 231/2017), no figuran dentro de ellas los recursos naturales, situación que queda palmaria al incluirse en el inciso b del mencionado artículo los bienes públicos enumerados en los artículos 234 y 235 del Código Civil y Comercial de la Nación, omitiéndose la expresa inclusión del art. 236 del precitado cuerpo normativo. Esto implica desvirtuar y deformar todo el régimen vigente en torno a la protección legal de los recursos naturales, renunciando el gobierno nacional a la defensa de inmunidad soberana, avasallando las competencias, facultades y dominio de las jurisdicciones provinciales y comprometiendo bienes colectivos, de dominio originario. Claramente estos recursos naturales no responden a la clasificación bienes públicos o privados, sino que adquieren su propia ontología: bienes ambientales (colectivos) y conforme las propias pautas de interpretación y aplicación del derecho (arts. 1 y 2 del Código Civil y Comercial) y de una visión sistémica de nuestro ordenamiento jurídicos dichos bienes tienen la propia consagración de ser recursos naturales y bienes ambientales y como tales fuera del comercio, indisponibles, inembargables y no se los puede desafectar, tal como se pretende con los decretos del Estado Nacional. Por otro lado, encontramos el Decreto $368 / 2019^{30}$ que desnaturaliza lo que antes era una excepción conforme el art. 6 de la Ley $22.531^{31}$ y a la par de ello se establece el llamado Programa

\footnotetext{
${ }^{29}$ Decretos por parte del PEN (Decretos $N^{\circ} 29 / 2017$ y 231/2017) que son palmariamente inconstitucionales, incongruentes con el ordenamiento jurídico, contrarios a nuestra autonomía y ejercicio de la jurisdicción que nos compete y violatorios del reconocimiento del dominio originario de los recursos naturales.

${ }^{30}$ Por el cual se traslada a la Secretaría de Gobierno de Ambiente y Desarrollo Sustentable de la Secretaría General De La Presidencia De La Nación o al órgano que en el futuro la reemplace, las competencias que surgen del artículo $6^{\circ}$ de la Ley $\mathrm{N}^{\circ} 22.35$, habilitando lo que antes era excepcional: la instalación de obras de infraestructura en los Parques Nacionales.

31 "La infraestructura destinada a la atención del visitante de los Parques Nacionales y Monumentos Naturales se ubicará en las Reservas Nacionales. De no ser posible prestar desde éstas una adecuada atención, la que se sitúe, con carácter de excepción, en los Parques Nacionales se limitará a lo indispensable para no alterar las condiciones del estado natural de éstos. A tales fines y siempre que resulte justificado en virtud de un interés general manifiesto, el Poder Ejecutivo Nacional a propuesta de la Administración de Parques Nacionales que exprese que no significará una modificación substancial del ecosistema del lugar, podrá acordar, mediante Decreto singular, autorización para construir edificios o instalaciones destinados a la actividad turística, y, en tal caso, se faculta al Poder Ejecutivo Nacional a otorgar -con todos los mencionados recaudos- concesiones de uso, de hasta treinta años".
} 
"Oportunidades Naturales"32 como política pública de incentivo a la inversión privada en áreas naturales, buscando desarrollar proyectos de ecoturismo so pretexto de generar nuevas oportunidades de desarrollo y fomento de economías regionales para las comunidades anfitrionas ${ }^{33}$, los cuales serán "una oportunidad para acompañar a la Argentina en su vocación de ofrecer productos turísticos memorables que exportan naturaleza al mundo" y responder a la demanda turística mundial que encuentra en el turismo de naturaleza una nueva manera de entender la visita a un destino turístico.

La oferta internacional tiene un sugerente subtítulo "Escenarios de una belleza única para el desarrollo de servicios turísticos en la naturaleza". Lo complementa con un la siguientes frase poética: "Descubrí de Norte a Sur, en el Litoral de los grandes ríos, entre selvas de altura y valles encantados, bajo un cielo de mil estrellas, entre antiguos paisajes que parecen de otro planeta, en las serranías del Centro y atravesando bosques como de cuentos, con lagos turquesas custodiados por cumbres emblemáticas, rodeados de glaciares, por caminos que llevan hasta el fin del mundo, el lugar para tu próxima inversión: Argentina, destino de naturaleza".

\section{Derecho al ambiente sano como discurso pro- MOTOR E INSTRUMENTO PARA LA DEFENSA DE LOS DERECHOS HUMANOS}

Corolario de lo expuesto se evidencia que "el paradigma y los criterios sobre los que se asienta el Derecho nacional e internacional de los derechos humanos, en el marco de la globalización, no resultan operativos en las condiciones y lógicas

\footnotetext{
${ }^{32}$ Disponible en https://www.argentina.gob.ar/oportunidades-naturales/politica-publica

${ }^{33}$ Dentro de los objetivos se enumeran : Posicionar a la Argentina como destino natural; Mejorar la competitividad, incrementando la llegada de turistas y el ingreso de divisas por el turismo; Dinamizar las economías regionales e integrar comunidades locales; Generar empleo e inclusión de mano de obra directa e indirecta en la cadena de valor; Promover actividades turísticas sustentables; Desarrollar nuevas áreas de inversión a través de tipologías de proyectos; Fomentar experiencias exclusivas de vivencias en la naturaleza.
} 
que imponen hoy día las economías de mercado y las sociedades burguesas dominantes" 34 .

De allí la necesidad de un proceso de refundición constante: el derecho es un sistema dinámico, abierto a nuevas realidades y opera como agente de transformación; específicamente en el ámbito ambiental es necesario replantearse los moldes y estructuras impuestos. Más que transformar y trasplantar modelos y teorías se debe buscar reformular, redefinir, readaptar, de lo contrario siempre algo quedará normalizado, hegemónico, sin reproducir las nuevas necesidades, que son justamente la de estos grupos acallados, excluidos y marginados.

"La experiencia de la subordinación se halla tras la idea de la igualdad. (...) El igualitarismo no es tanto su traducción de hechos como un intento por escapar de las condiciones que las generan. El objetivo del igualitarismo político es una sociedad libre de dominación. El afán de articular un planteamiento completo de la justicia o una defensa de la igualdad mediante la multiplicación de los derechos, pronto convierte en una farsa aquello que se va multiplicando (...). Ciertamente, los individuos poseen derechos, pero éstos no son resultado de nuestra común humanidad; son el resultado de una concepción compartida de los bienes sociales: su carácter es local y particular" ${ }^{\text {"35. }}$. "Nos encontramos con la necesidad de implantar una nueva racionalidad jurídica, basada en la alteridad y el bien común, lo mismo que se debe articular un nuevo paradigma económico alternativo, que no reduzca el valor de las cosas a simple precio de mercado ni la actividad humana a mero comercio (...) favorezcan el reconocimiento y la protección de espacios no susceptibles de ser comercializados en los términos de la lógica del capitalismo. (...) Nada que sea básico para la supervivencia humana puede ser objeto de monopolio y de privatización" ${ }^{\prime 36}$.

\footnotetext{
${ }^{34}$ Sánchez Rubio, David (2005). "En torno a la reversión del Derecho y de los derechos humanos: mercado, biodiversidad, patrimonio común de la humanidad y especificidad indígena”, CLACSO, pág. 2

${ }^{35}$ Wazler, Michael. Las esferas de la justicia. Una defensa del pluralismo y la igualdad. Fondo de Cultura Económica, Prefacio, págs. 9-13.

${ }^{36}$ Sánchez Rubio, David (2005). Ob. Cit., págs. 8 y 9.
} 
Propender a una deconstrucción de las interpretaciones hegemónicas de qué es la biodiversidad, el valor de los recursos naturales, la dominiabilidad y apropiación de los recursos y bienes ambientales. Repensar las categorías de bienes comunes, bienes sociales y ambientales, es desde allí que se puede lograr un viraje de timón. Esto plantea la necesidad de legitimar la pluralidad de intereses colectivos e individuales dispares y de diferentes formas de entender los bienes ambientales que entran en constante tensión con ideologías totalizadoras, contrarias a dicha legitimidad (tensiones que se plantean entre los derechos individuales y los colectivos, en considerar una nueva función de la propiedad: la función ambiental, en el reconocimiento de nuevos derechos, nuevos actores que reclaman ser oídos, protegidos y reconocidos ante estas ideologías dominantes): "No se trata de cómo deberíamos definir los derechos sino de cómo deberíamos sentirnos respecto al discurso en el que los reclamamos"37. Que el diálogo entre el derecho y el medio ambiente conduzca a una transformación o revisión de los estándares jurídicos tradicionales. Una teoría que pretende ser totalizadora, omnipresente y ahistórica se olvida o soslaya los conocimientos sito locales, ese es el precio que se paga por mercantilizar ámbitos que deberían estar fuera del mercado ${ }^{38}$. Los problemas ambientales tienen la particularidad de no ocurrir en vacíos sociales y rozan los más profundos intereses de humanidad, lo que nos genera el siguiente interrogante ¿es natural porque es socialmente aceptado o lo aceptamos porque esta naturalizado, normalizado? El derecho ambiental conlleva una revisión epistemológica capaz de operar sobre el discurso jurídico, a socavar los cimientos sobre los que se asiente el discurso jurídico, repensar nuevas subjetividades ${ }^{39}$ y avanzar más allá, en reclamar nuevos derechos, en considerar a los grupos vulnerables, entre los que encontramos los movimientos sociales que luchan por la defensa del medio ambiente, por la protección de los débiles, de los ausentes: "mucho de lo que no existe en nuestra sociedad es producido activamente como no existente, y por

\footnotetext{
${ }^{37}$ Keneddy, Duncan (2010). Izquierda y Derecho. Ensayos de teoría jurídica crítica. Ed. Siglo veintiuno, Buenos Aires.

${ }^{38}$ Esto no implica "cristalizar" los recursos naturales ni oponerse a planes de desarrollo ni inversión, sino armonizar ambas dimensiones a través de controles y monitores, contratos y proyectos protectorios y respetuosos de la normativa ambiental.

${ }^{39}$ Un claro ejemplo es el reconocimiento de las generaciones futuros (equidad inter-intra generacional), nuevos derechos de la naturaleza.
} 
eso la trampa mayor para nosotros es reducir la realidad a lo que existe. Así, de inmediato compartimos esta racionalidad perezosa, que realmente produce como ausente mucha realidad que podría estar presente"40.

De lo expuesto podemos inferir que pese a la consagración universal e igualitaria del derecho humano al ambiente sano en la práctica se observan continuamente prácticas y hechos que tienden a naturalizar y cristalizar situaciones de desventaja, exclusión social, cultural y ambiental. Podemos intuir que, en gran parte, esto se debe a que el propio lenguaje de los derechos humanos y como expresión de ello, el derecho al ambiente sano, son reproducidos bajo un sistema y modelo imperante (monopolizador) que soslaya la existencia de la interculturalidad, la dimensión social y colectiva, el particularismo y localización de estos derechos más allá de su reconocimiento universal, donde el propio discurso de los derechos humanos funciona como un instrumento representativo de ciertos grupos de poder y modelos culturales ${ }^{41}$.

El papel del derecho depende, pues, de una relación de fuerzas en el marco del conflicto social. En manos de grupos dominantes constituye un mecanismo de preservación y reconducción de sus intereses y finalidades, en manos de grupos dominados, un mecanismo de defensa y contestación política, por lo tanto, de cambio social. La problemática de los derechos humanos, tan conspicua en este momento, puede proporcionar un ejemplo de lo expresado. Las declaraciones de derechos y garantías consagradas por las legislaciones modernas, las más de las veces con alcance puramente formales, pudieron ser miradas por esto mismo, con cierto escepticismo. Miradas sólo como recurso legitimante y tranquilizador que prometía lo que precisamente no otorgaba. Sin embargo, en momentos de grave crisis, en que los niveles de conflicto se acentúan, ese discurso meramente ideológico se transforma en una formidable herramienta de lucha, de denuncia y de resistencia a la opresión ${ }^{42}$.

\footnotetext{
${ }^{40}$ De Sousa Santos, Boaventura (2006). Renovar la teoría crítica y reinventar la emancipación social, CLACSO, Buenos Aires, pág. 23.

${ }^{41}$ Este tipo de posturas hace imposible que derechos humanos pueda ser un discurso generado y aceptado por otras culturas para la defensa de la dignidad humana, y los coloca en la peligrosa situación de convertirse en un instrumento de ideologización que justifique la imposición de una cultura en perjuicio y destrucción de otras. Rosillo Martínez, Alejandro (2016). "Repensar derechos humanos desde la liberación y la descolonialidad", Revista Direito e Práxis, Rio de Janeiro, Vol. 07, N. 13, pág. 724.

${ }^{42}$ Cárcova, Carlos María (2003). "Notas acerca de la Teoría Crítica del Derecho", en Revista Jurídica Universidad Interamericana de Puerto Rico (Septiembre - Diciembre), pág. 8.
} 
Pero a la vez que cumple un rol formalizador y reproductor de las relaciones establecidas, [los derechos humanos] también cumple un rol en la remoción y transformación de tales relaciones. Posee a la vez, una función conservadora y renovadora. Ello es así, porque como discurso ideológico elude, pero también alude. Al ocultar, al disimular, establece al mismo tiempo el espacio de una confrontación. Cuando promete la igualdad ocultando la efectiva desigualdad, instala, además, un lugar para el reclamo por la igualdad ${ }^{43}$.

Son definiciones culturales que adquieren significación en tanto están contextuadas dar lugar al disenso, a la participación de nuevos actores sociales que reclaman derechos tan legítimos como los tradicionales y atrincherados derechos, es ampliar el abanico de realidades, reconocer nuevos valores (que acompañar al sistema normativo) pero que se enraíza con las emociones, con los sentidos, en ese imaginario social, que busca que los problemas sean solucionados: "nuestro primer problema para la gente que vive en el sur es que las teorías están fuera de lugar: no se adecuan realmente a nuestras realidades sociales" ${ }^{44}$.

\section{LA OTRA CARA DE LA COLONIALIDAD: COSTOS (PASIVOS) SOCIALES-AMBIENTALES}

La propia Corte Interamericana "toma en cuenta que la afectación a estos derechos puede darse con mayor intensidad en determinados grupos en situación de vulnerabilidad. Se ha reconocido que los daños ambientales "se dejarán sentir con más fuerza en los sectores de la población que ya se encuentran en situaciones vulnerables", por lo cual, con base en "la normativa internacional de derechos humanos, los Estados están jurídicamente obligados a hacer frente a esas vulnerabilidades, de conformidad con el principio de igualdad y no discriminación" $"$.

Sus efectos repercuten con más fuerza en sectores de población con preexistentes situaciones de vulnerabilidad, que requieren una protección ambiental equitativa contra la "discriminación socio-territorial" y la "desigualdad ambiental",

\footnotetext{
${ }^{43}$ Ibídem, pág. 8

${ }^{44}$ De Sousa Santos, Ob. Cit., pág. 15. Boaventura (2006).

${ }^{45}$ Opinión Consultiva, Ob. Cit., párraf. 67.
} 
así como respuestas más eficaces en los procesos de evaluación de impacto ambiental y social, los que deben ponderar esta variable. En estos casos, ciertos sesgos en la valoración de la línea de base socio ambiental preexistente, sumado a asimetrías de poder, suelen desembocar en una clara discriminación ambiental en los procesos de evaluación de impacto ambiental ${ }^{46}$.

Estos grupos desaventajados generalmente no son responsables de su propio escenario, y por lo general se encuentran en la imposibilidad de influir en aquellas decisiones o conductas que originan o perpetúan su exclusión estructural, es decir, que son ajenos a los procesos de toma de decisiones políticas ${ }^{47}$.

Lo que genera la movilización de los ciudadanos directamente afectados y el rechazo de la instalación de nuevos proyectos es la desigualdad en la distribución de la carga de la contaminación, lo que implica la exposición a un riesgo desproporcionado por ciertos sectores o grupos de la sociedad, encontrándose un determinado grupo "obligado" a soportar los riesgos ambientales generados por toda la sociedad. Esos riesgos que son inaceptables para la comunidad en general son soportados por algunos.

Una de las causas de los conflictos es la percepción de los graves daños ambientales causados y los escasos (o mejor dicho) nulos beneficios que, como contrapartida, han recibido las comunidades locales. En los conflictos, se evidencia la polarización de las posiciones de las comunidades locales en torno a la localización y/o desarrollo de emprendimientos.

Esto (en parte) se debe a que en la ejecución de los proyectos se relega a las comunidades afectadas, las cuales son desplazadas por "intereses superiores", no habiendo una justa y equitativa distribución de los costes y beneficios en el desarrollo de planes y proyectos, convirtiéndose en grupos no solo afectados sino también vulnerables, por la solo condición de vivir en el radio de afección de los planes de inversión y desarrollo. Dicha situación se agrava cuando el medio ambiente no es debidamente conservado y remedido, siendo que los costos y

\footnotetext{
${ }^{46}$ Morales Lamberti, Alicia (2015). "Los derechos humanos en el Código Civil y Comercial, como fuentes de integración hermenéutica y reconocimiento axiológico en la aplicación del derecho ambiental", en Revista de Derecho Ambiental, Ed. Abeledo Perrot, Julio-Septiembre 2015, Nº 43, págs. 43-139.

${ }^{47}$ Saba, Roberto (2007). “(Des)igualdad estructural”. En R. Gargarella, \& M. Alegre, El Derecho a la Igualdad. Aportes para un constitucionalismo igualitario. Buenos Aires: Abeledo Perrot.
} 
riesgos son externalizados, afectándose al ambiente per se e indirectamente los derechos de las comunidades que habitan en esa zona de afectación.

En ese contexto se analizan los pasivos ambientales ${ }^{48}$ como problemática que incide en las perspectivas del derecho al ambiente sano -apuntadas inicialmente-. A los fines operativos del presente trabajo adoptamos la siguiente definición de PA: un PA refiere a la existencia de una obligación legal de asumir la remediación de impactos ambientales no mitigados o por el riesgo de que un daño ambiental se configure; es producto de actividades desarrolladas en el pasado y/o en el presente -puede ser consecuencia de una contaminación histórica, pretérita o responder a una situación actual-, que generan un efecto acumulativo y progresivo (con el transcurso del tiempo) y que representan un potencial riesgo para el medio ambiente, para la salud, vida de las personas, ante la existencia de un daño ambiental de incidencia colectivo o el riesgo que el mismo se materialice.

De la existencia de un PA se deriva la necesidad de remediación, saneamiento, mitigación o compensación por encontrarnos ante áreas o sitios contaminados, en los que se superan los umbrales tolerables de contaminación (sea del agua superficial, subterránea, suelo, subsuelo, atmósfera, eliminación de residuos); en los que no se encuentran debidamente gestionados los posibles impactos negativos, por lo que se configura un potencial riesgo de daños para la salud, calidad de vida, propiedad (daños patrimoniales y extra patrimoniales producto de la situación de contaminación) y para los bienes y servicios ambientales. Es decir, que podemos asimilar un PA a un sitio contaminado como consecuencia de una actividad o conducta, realizada en el presente (actual) o que fue realizada en el pasado (pretérita), pero que, en uno u otro caso, puede afectar el ambiente de manera adversa, lo que conlleva la obligación de incurrir en costos tendientes a la remediación de ese sitio.

De lo expuesto y a los fines de caracterizar un PA, enunciamos los siguientes elementos ${ }^{49}$ : a) Es un sitio que no se encuentra remediado; b) La situación fáctica

\footnotetext{
${ }^{48}$ En adelante PA.

${ }^{49}$ Doroni, Georgina (2018). "Pasivos ambientales en el contexto del derecho humano al ambiente sano. La exigencia de remediación de los PA: participación ciudadana y contextos de desigualdad socio-ambiental", en Cuaderno de Derecho Ambiental N ${ }^{\circ}$ X - Derechos Ambiental y Derechos Humanos, Año 2018, IJ Editores, págs. 82-100.
} 
de la existencia de un PA conlleva una exposición permanente a una situación de riesgo, que continúa en el tiempo hasta tanto el sitio no sea saneado y remediado: la existencia del PA conlleva actualidad por sus propios efectos. c) Su existencia implica una "interferencia en el disfrute de un ambiente sin riesgos, limpio, saludable y sostenible, que puede tener repercusiones negativas, tanto directas como indirectas, en el disfrute efectivo de todos otros derechos humanos" ${ }^{\circ 0}$; d) Esta situación fáctica actual idónea para producir un daño fututo o un riesgo potencial implica un deterioro progresivo en el tiempo: el efecto proyectivo, acumulativo y sinérgico $^{51}$ es ínsito a la generación, acumulación y/o abandono sin las correctas medidas de cierre y mitigación de un PA. e) Implica un conjunto de impactos negativos perjudiciales para el medio ambiente, la salud, calidad o vida digna, ocasionados por determinadas obras, actividades o conductas, existentes en un determinado período de tiempo (lo que refuerza la idea de la temporalidad, ya sea presente o pasada); f) Configura un riesgo potencial y permanente susceptible de configurar un daño ambiental colectivo, afectando bienes y servicios ambientales y derechos individuales (patrimoniales o extrapatrimoniales) como daño rebote, indirecto $^{52}$; g) Supone una obligación legal de pagar una suma de dinero o incurrir en un gasto (costo) derivado de asumir la remediación de impactos ambientales no mitigados; por tanto, exige la necesidad de remediación.

\footnotetext{
${ }^{50}$ Naciones Unidas, Asamblea General: Resolución aprobada por el Consejo de Derechos Humanos el 24 de marzo de 2017. 34/20. Los derechos humanos y el medio ambiente, A/HRC/RES/34/20.

${ }^{51}$ Comisión IDH: Informe $n^{\circ}$ 69/04, petición 504/03. Admisibilidad comunidad de San Mateo de Huanchor y sus miembros (Perú), 15 de octubre de 2004: La grave contaminación ambiental ocasionada por la cancha de relaves mineros había generado una crisis de salud pública en la Comunidad de San Mateo de Huanchor y que cada día aumentaba el riesgo asociado a la exposición a los metales contenidos en los relaves (...) los efectos de la exposición de los relaves en el transcurso del tiempo se han prolongado y se agudizan al no recibir el tratamiento adecuado (...). El resaltado me pertenece, para hacer énfasis en el elemento temporal.

52 "El daño ambiental es una expresión ambivalente, pues designa no solamente el daño que recae en el patrimonio ambiental que es común a una comunidad, en cuyo caso hablamos de impacto ambiental, sino que se refiere al daño que el medio ambiente ocasiona de rebote (par richochet), a los interés legítimos de una persona determinada, configurando un daño particular, que ataca a un derecho subjetivo y legitima al damnificado para accionar en reclamo de una reparación o resarcimiento del perjuicio patrimonial o extrapatrimonial que le ha causado". Cámara Federal de Apelaciones de la Plata Sala II. Autos "Mazzeo, Alicia S. y otro v. YPF SA". Sentencia de fecha 12 de julio de 2012. Cfr. Cafferatta, Néstor A. "Ley 25675 General del Ambiente. Comentada, interpretada y concordada", DJ 2002-3-133 y en "Daño ambiental colectivo y proceso civil colectivo - Ley 25675-“, RCyS 2003-80.
} 
A través de esta caracterización se puede inferir que la existencia de PA implica una afectación constante al derecho al ambiente sano, la cuestión es compleja: la afección recae en derechos de incidencia colectiva, de predominante base social, que requiere inexorablemente una mirada hacia el pasado que se arrastra hacia el futuro. A su vez, "el concepto de pasivo ambiental tiene importancia social, en tanto que su existencia, cuantificación y necesidad de remediación se está afirmando cada vez más, en diferentes contextos de lucha de la sociedad civil y colectivos sociales.

Desde una dimensión social, una primera relación que aparece evidente en el tema de pasivos ambientales y sitios contaminados es con la pobreza ${ }^{53}$ : estos tienden a coincidir espacialmente" ${ }^{54}$.

Toda distribución es justa o injusta en relación con los significados sociales de los bienes de que se trate. La cuestión de fondo es entrever ¿quiénes determinan el significado y significante de los bienes, ¿es la clase dominante? ¿Se persuade en el significado? No debemos perder de vista que es todo en base a la famosa lucha por el derecho, es decir, hay una producción social, cultural e histórica, que lleva a revertir u otorgar nuevos significados.

Las obligaciones de derechos humanos relacionadas con el medio ambiente incluyen la obligación general de no discriminar en su aplicación ${ }^{55}$. Sin embargo, "los bienes y cargas (impactos y riesgos) ambientales no se distribuyan equitativa y proporcionalmente dentro de una determinada comunidad (desde una percepción

\footnotetext{
${ }^{53}$ Considero que el término pobreza queda acotado y debe ser abordado desde una concepción integral y actual, ampliado más bien a situaciones de vulnerabilidad socio-ambiental, que exceden una cuestión meramente económica. "Frecuentemente se identifica la condición de pobreza de la gente con vulnerabilidad. Sin embargo, la inseguridad e indefensión que caracterizan a ésta no son necesariamente atribuibles a la insuficiencia de ingresos, propia a la pobreza. (...) El concepto de vulnerabilidad parece ser el más apropiado para comprender el impacto transformador provocado por el nuevo patrón de desarrollo en el plano social y para captar esa mayor exposición a riesgos en que se encuentra una gran masa de los habitantes de América Latina en el actual período histórico". Pizarro, Roberto. La vulnerabilidad social y sus desafíos: una mirada desde América Latina. CEPAL, ISSN 1680-8770, Santiago de Chile, Febrero 2001, págs. 7-8.

${ }^{54}$ Morales Lamberti, Alicia (2008). Gestación y remediación de Pasivos Ambientales. Alveroni, Córdoba, pág.6. pp.3-237.

${ }^{55}$ Morales Lamberti, Alicia (2014). Evaluación de impacto ambiental y social: estándares sustantivos y de procedimiento en el Sistema Interamericano de derechos humanos. En cuaderno de derecho ambiental $\mathrm{N}^{\circ} \mathrm{VI}$, pág. 102. 71-110.
} 
de las generaciones presentes y futuras) y han sido invariablemente asumidas por los sectores más vulnerables de la población (...)" ${ }^{\text {56 }}$.

"El aspecto distributivo - la distribución equitativa y proporcional de los bienes y pasivos ambientales- no es más que una aplicación concreta del principio de igualdad y de la garantía de no discriminación" 57 , agravada en muchos casos por la no adopción de una política concreta de gestión y remediación de PA, por la deficitaria supervisión y fiscalización por parte de las autoridades de control, por el no cumplimiento de medidas adecuadas de tratamiento, disposición final, cierre y pos cierre seguro que derivaría en una continuidad y permanencia de prácticas discriminatorias e inequitativas, que implicarían una vulneración del derecho al medio sano (tanto desde su dimensión individual como colectiva).

Justamente, el término "daño colateral" empleado por Bauman hace referencia a la idea de que "son efectos no intencionales, que no obstante son dañinos, lesivos y perjudiciales, lo que sugiere que esos efectos no fueron tomados en cuenta cuando se planeó la operación; o bien que se advirtió y ponderó la posibilidad de que tuvieran lugar dichos efectos, pero, no obstante, se consideró que el riesgo valía la pena: y esta segunda opción es mucho más previsible (y mucho más probable) si se tiene en cuenta que quienes decidieron sobre las bondades del riesgo no son los mismos que sufrirán sus consecuencias. (...) los daños colaterales suponen, de forma tácita, una desigualdad ya existente de derechos y oportunidades, en tanto que acepta a priori que la distribución desigual de los costos que implica emprender una acción (...) En apariencia los riesgos son neutrales y no apuntan a un blanco determinado, por lo cual sus efectos son azarosos; sin embargo, en el juego de los riesgos, los dados están cargados" $" 58$.

La prolongación (temporo-espacial) de sitios sin la debida remediación, con el nivel de riesgo que conllevan implicaría la consolidación y permanencia de una situación de exclusión y desigualdad ambiental, y dependiendo del caso concreto

\footnotetext{
${ }^{56}$ Medio ambiente y derechos humanos: justicia ambiental y el caso de Rinconada de Maipú, pág. 356. [en línea]https://www.fundacionhenrydunant.org/images/stories/biblioteca/Medio_Ambiente_Cambio_Climatico_ Derechos_Humanos_y_Desarrollo/Medio_Ambiente_y_Derechos_Humanos_Justicia_Ambiental_caso_ Rinconada_Maipu.pdf[consulta: 5 de julio de 2019].

${ }^{57}$ Ibidem, pág. 357.

${ }^{58}$ Bauman, Zygmunt (2015). Daños colaterales. Desigualdades sociales en la era global. Fondo de Cultura Económica, México, págs.13-14.
} 
también social, ya que en la mayoría de los casos no hace más que reforzar la situación de vulnerabilidad por la que atraviesan esos grupos que se enfrentan a una situación de contaminación ambiental. Esto se debe a que los costos de la contaminación vulneran el acceso al derecho a un ambiento sano, derechos que en este caso es restringido a quienes viven en sitios contaminados y a la vez vulnera la propia capacidad de regeneración y autorregulación de los procesos ecológicos.

\section{INSTANCIAS DE PARTICIPACIÓN SOCIAL}

En ese contexto es que se presenta la relevancia, necesidad y exigencia de la participación social-local en las medidas y planes de resolución y gestión de los PA. Esa participación en las instancias de reparación, remediación o recomposición reafirma, refuerza y enriquece la interconexión del medio ambiente y los derechos humanos. Las tareas de remediación tienen por objeto el plano ambiental-ecológico, lo que se busca recomponer es el medio ambiente dañado y correlativamente esas medidas apuntan a mejorar y asegurar los niveles de calidad de vida de las personas que habitan en esos sitios, lo que es comprensivo de la perspectiva del derecho al ambiente sano como derecho humano y también de la connotación colectiva y social de ese derecho.

Se propone el ejercicio del derecho de participación social-ciudadana en las decisiones, proyectos y planes que se adopten en torno a la remediación de sitios contaminados, con el aditamento que se evidencia una relación de causalidad y condicionalidad entre estos sitios y contextos de desigualdad socio-ambiental.

La primera obligación de "efecto inmediato" derivada de los derechos económicos, sociales y culturales consiste en garantizar que se ejercerán en condiciones de igualdad y sin discriminación (...) y evitando diferencias de trato arbitrarias. En este caso se trata de diferencias por el hecho de estar próximos a sitios contaminados o lugares donde se emplazan los proyectos o actividades, lo que constituye una situación de vulnerabilidad.

"La «discriminación socio-territorial» y la «desigualdad ambiental» suele evidenciarse en los proyectos" de remediación, cuya evaluación requiere "valorar 
la preexistencia de situaciones de pobreza, marginación, discriminación social o segregación racial, que coinciden con una mala calidad ambiental o riesgosos (...)"."En este contexto, ha sido particularmente difícil generar espacios de diálogo para la búsqueda de soluciones de consenso que hagan posible, por un lado, la adopción de medidas concretas orientadas a mejorar la gestión ambiental de PA; y por otro, que viabilicen avances en la efectividad de la legislación para lograr una mejor protección de la salud y el ambiente afectados".

Por eso se requiere también que los Estados reconozcan que existen sectores que se encuentran en desventaja en el ejercicio de los derechos sociales y ambientales, y adopten políticas y acciones positivas para garantizarlos, en especial las acciones para el reconocimiento y extensión de tales derechos a aquellas personas pertenecientes a sectores históricamente discriminados ${ }^{59}$.

La importancia del control y licencia social en esta etapa final de remediación implica dar paso a una compresión sistémica de las variables de vulneración a la que se encuentran estos grupos y sectores ${ }^{60}$, lo que debería contribuir a un mejor diseño e implementación de políticas dirigidas a evitar o reducir los daños que pueden padecer y padecen los sistemas humanos (sociales) y ecológicos producto de sitios no remediados. El derecho a la consulta que tiene por objeto garantizar la participación en la adopción de las decisiones que afectan a las comunidades

\footnotetext{
${ }^{59}$ Organización de Estados Americanos, Comisión Interamericana de Derechos Humanos. "Lineamientos para la elaboración de indicadores de progreso en materia de derechos económicos, sociales y culturales", OEA/ Ser.L/V/II.132, Doc. 14, 19 julio 2008, párraf. 48-50, pág. 21-22.

60 "Quienes más sufren los efectos de la contaminación y tienen menos acceso a los recursos naturales vitales son las poblaciones más vulnerables, (...) en una situación absolutamente asimétrica de desigualdad respecto al resto de la población". Desigualdad existente, que se percibe tanto en términos del mayor impacto de la contaminación que sufren las poblaciones más vulnerables y el menor acceso que experimentan a los recursos vitales. Usualmente, las personas que habitan o suelen asentarse en los territorios con mayor riego ambiental (periferias urbanas, laderas de ríos altamente contaminados, zonas anegable, cercanías de depósitos de residuos) son personas que se encuentran en condiciones de vulnerabilidad, pobreza o con escases oportunidades. En Latinoamérica, la realidad no deja lugar a dudas de que aquellos ámbitos y cuencas más contaminadas presentan poblaciones segregadas, marginales y asumen una complejidad que vincula directamente a los grupos sociales más vulnerables con las realidades de contaminación en un formato de discriminación económica, social y ambiental. Di Paola, Ma. Eugenia, "Inclusión, sociedad y sustentabilidad: ¿Cuánto tiempo más llevará? En Derecho Ambiental. Dimensión social (Dir.Cafferatta Néstor A), Rubinzal- Culzoni, 2015, págs. 215-216.
} 
no puede consistir en una simple información a dichos entes colectivos, sino que debe propiciar espacios de concertación.

Es de destacar la terminología empleada por Camps quien refiere a control popular, terminología que evidencia la necesidad de un control y seguimiento permanente de los objetivos a cumplir, con un plan o programa de ejecución y una amplia participación de los sectores perjudicados.

El saneamiento y remediación de los PA implicaría la recuperación de los bienes ambientales afectados y no puede ser restringido en términos meramente patrimoniales o financieros, sino que debe ser comprensivo también de la lesión de intereses más generales, de naturaleza eminentemente social-colectiva ${ }^{61} \mathrm{y}$ ambientales-ecológicos, lo que incorpora o mejor dicho pluraliza las escalas de valoración.

La recomposición ambiental demanda una planificación que defina escenarios de remediación, objetivos generales y particulares, líneas de base, metas intermedias y finales, actividades, plazos de ejecución, presupuesto y financiamiento de cada proyecto. Sumado a esto, es necesario un monitoreo con indicadores específicos, acceso a la información pública y un esquema de participación social. Debe reflejarse en un verdadero proceso de consulta y validación social ${ }^{62}$

En los extractos anteriores encontramos la justificación de la necesidad del derecho de participación social en los procesos de remediación y/o recomposición del medio ambiente dañado. La importancia del control y licencia social en esta final de remediación implica dar paso a una compresión sistémica de las variables de vulneración a la que se encuentran estos grupos y sectores, lo que debería contribuir a un mejor diseño e implementación de políticas dirigidas a evitar o reducir los daños que pueden padecer y padecen los sistemas humanos (sociales) y

\footnotetext{
${ }^{61}$ Cfr. Morales Lamberti, Alicia. "Remediación de pasivos ambientales de la minería de uranio: Deuda ecológica y social", págs. 50-53.

URL: http://revistas.bibdigital.ucc.edu.ar/ojs/index.php/RFD/article/viewFile/735/587[consulta: 5 de julio de 2019].

Acumar, Informe Final sobre Consulta ciudadana sobre el documento "Identificación de áreas prioritarias para intervenciones en la Cuenca Matanza Riachuelo - Análisis de riesgo ambiental”, septiembre 2018, pág. 32.

${ }^{62}$ Acumar, Informe Final sobre Consulta ciudadana sobre el documento "Identificación de áreas prioritarias para intervenciones en la Cuenca Matanza Riachuelo - Análisis de riesgo ambiental”, septiembre 2018, pág. 32.
} 
ecológicos producto de sitios no remediados. De todos modos, cuando hablamos de un consenso racionalmente motivado, ¿según quién?, ¿según qué intereses? El riesgo de los consensos es caer nuevamente en la imposición de un discurso a quienes no sean escuchados, están acallados, ausentes. Esto nos encierra en un problema cíclico: la historia del reparto del poder y su correlación en lo social, lo que evidencia que las instancias de participación meramente formales o con la simple realización para conformar un requisito solo genera una nueva victimización y acentúa la discriminación que subyace.

\section{CONCLUSIONES}

A partir de la interacción entre los derechos humanos y el medio ambiente se determinaron las siguientes perspectivas de análisis del derecho humano al ambiente sano: a) por un lado, se traduce en la expresión clásica e individualista del derecho a un ambiente sano como derecho humano natural e individual, ínsito a la condición de ser humano y vinculada con el disfrute de otros derechos humanos (protección vía indirecta); b) por otro lado, implica un derecho de dimensión social (emplazamiento social del derecho) y colectiva (la defensa de los derechos humanos responde a un interés público y en este caso con vocación colectiva $)^{63}$, c) y bajo esta misma lógica debiera traducirse y emplazarse el derecho en una dimensión ecológica, reconociendo la existencia del derecho a la reparación del medio ambiente per se.

Estas perspectivas nos interpelan a replantearnos actuales debates jurídicos, sociales, políticos, ambientales, culturales en torno a la relación e interdependencia entre los derechos humanos y el medio ambiente, a superar visiones encorsetadas y desarrollar un giro lingüístico: derecho humano al ambienta sano, ¿y el derecho del medio ambiente a permanecer sano? Es reconocer la función social, ambiental y ecológica de los derechos.

En virtud de esa relación y particularmente en los casos de contaminación ambiental, enfocándonos principalmente en la existencia de pasivos ambientales

${ }^{63}$ Cfr. Morales Lamberti, "Los derechos humanos en el Código Civil y Comercial, como fuentes de integración hermenéutica y reconocimiento axiológico en la aplicación del derecho ambiental”, en Revista de Derecho Ambiental № 43, AbeledoPerrot, Junio-Septiembre 2015, págs. 139-164. 
(sitios contaminados) es que surge el interrogante de analizar si contar con el derecho humano a un ambiente sano implica reconocer, así más no sea implícitamente, un derecho humano a la reparación o remediación del medio ambiente a los fines de mantener ese estándar de ambiente sin riesgos, limpio, saludable y sostenible.

Reparación que comprende, por un lado, el componente social que subyace en el fondo del análisis: la desigualdad socio-ambiental que sufren ciertos sectores soportando la existencia de sitios contaminados; y por otro, el componente ambiental (ecológico). De esta manera, ante la existencia de pasivos ambientales el derecho humano al ambiente sano parecería ser el derecho de unos pocos. Usualmente, las personas que habitan o suelen asentarse en los territorios con mayor riego ambiental (periferias urbanas, laderas de ríos altamente contaminados, zonas anegable, cercanías de depósitos de residuos) son personas que se encuentran en condiciones de vulnerabilidad, pobreza o con escases oportunidades. En Latinoamércia, la realidad no deja lugar a dudas de que aquellos ámbitos y cuencas más contaminadas presentan poblaciones segregadas, marginales y asumen una complejidad que vincula directamente a los grupos sociales más vulnerables con las realidades de contaminación en un formato de discriminación económica, social y ambiental" ${ }^{64}$.

En este marco, se torna propicio y necesario la implementación de una política de gestión y remediación de los pasivos ambientales, a través de prácticas ambientales que sean más equitativas, eficaces y respetuosas de las preocupaciones de quienes se han visto más próximos y tenido que soportar daños ambientales. De allí la necesidad de que el derecho de consulta y participación (tal como se observa en los procedimientos de EIA) son iguales de necesarios en los mecanismos de adopción de medidas de remediación: escuchar a quienes son los afectados y beneficiados con dichas medidas. Generar espacios de participación en torno a la remediación de los pasivos (costos) ambientales y sociales generados como producto de la imposición de proyectos y planes de desarrollo e inversión, siendo "unos pocos" los que soportan los costes de la contaminación es un modo de contrarrestar la desigualdad socio-ambiental.

${ }^{64}$ Di Paola, Ma. Eugenia, "Inclusión, sociedad y sustentabilidad: ¿Cuánto tiempo más llevará? En Derecho Ambiental. Dimensión social (Dir.Cafferatta Néstor A),Rubinzal- Culzoni, 2015, págs. 215-216. 
La desigualdad socio-ambiental existente se percibe tanto en término del mayor impacto de la contaminación que sufren las poblaciones más vulnerables y el menor acceso que experimentan a los recursos vitales. Por otro lado, en las dificultades y las oportunidades que viven estos grupos para acceder a la toma de decisión en materia de planificación y desarrollo y la necesidad de una consideración integral de sus derechos.

Justamente la mercantilización de los recursos naturales y prácticas de constante de sobreexplotación de los bienes ambientales con la consecuente generación de PA conlleva la necesidad de replantear los discursos, teorías y prácticas que se revelan como la única opción posible o única alternativa y abrir el escenario a nuevos actores y espacios de concertación, sobre todo de aquellos que padecen una constante "desigualdad en la distribución espacial y social, tanto de los impactos medioambientales negativos como de aquellas implicaciones positivas derivadas de la aplicación de las normativas y políticas públicas en materia de medio ambiente" 65

${ }^{65}$ Arriaga Legarda, Alicia y Pardo Buendía, Mercedes (2009). "Justicia Ambiental. El estado de la cuestión”, Revista internacional de sociología (ris), Vol.69, nº 3, Septiembre-Diciembre 2009, pág. 628. 627-648 


\section{Bibliografía}

Arbour, Louise. Plan de acción presentado por la Alta Comisionada de las Naciones Unidas para los Derechos Humanos, A/59/2005/Add.3, 2006-2007.

Arriaga Legarda, Alicia y Pardo Buendía, Mercedes (2009). "JUSTICIA AMBIENTAL. El estado de la cuestión", Revista internacional de sociología (ris), Vol.69, $\mathrm{n}^{\circ}$ 3, Septiembre-Diciembre 2009, págs. 627-648

Bauman, Zygmunt (2015). Daños colaterales. Desigualdades sociales en la era global. Fondo de Cultura Económica, México.

Cárcova, Carlos María (2003). "Notas acerca de la Teoría Crítica del Derecho", en Revista Jurídica Universidad Interamericana de Puerto Rico (Septiembre - Diciembre).

Corte IDH, Opinión Consultiva OC-23/17, de 15 de noviembre de 2017, solicitada por la República de Colombia- Medio ambiente y derechos humanos.

De Sousa Santos, Boaventura (2006). Renovar la teoría crítica y reinventar la emancipación social, CLACSO, Buenos Aires.

Fundación ambiente y recursos naturales (2019). Pulso ambiental. Revista política y de debate $\mathrm{N}^{\circ} 12$, septiembre 2019.

Galafassi, Guido P. (2004). "Razón instrumental, dominación de la naturaleza y modernidad: la Teoría Crítica de Max Horkheimer y Theodor Adorno" en Revista Theomai, n9, primer semestre, pág. 101 [en línea] http://revista-theomai.unq.edu.ar/numero9/ artgalafassi\%28frankf\%299.htm [consulta: 5 de julio de 2019].

Galeano, Eduardo (2013). Las venas abiertas de América Latina, Buenos Aires: Siglo XXI Editores, pág. 180.

Gudynas, Eduardo (2010). "La senda biocéntrica: valores intrínsecos, derechos de la naturaleza y justicia ecológica", en Tabula Rasa. Bogotá - Colombia, No.13, julio-diciembre 2010, ISSN 1794-2489. 
Gudynas, Eduardo(2013), "Extracciones, extractivismos y extrahecciones.

Un marco conceptual sobre la apropiación de recursos naturales",

Observatorio del Desarrollo, No 18, Febrero 2013.

Guimarães, Roberto P (1998). "La ética de la sustentabilidad y la formulación de políticas de desarrollo", en Ambiente \& Sociedades, No. 2, Págs. 53-82.

Keneddy, Duncan (2010). Izquierda y Derecho. Ensayos de teoría jurídica crítica. Ed. Siglo veintiuno, Buenos Aires.

Lorenzetti, Ricardo L (2007). "La protección jurídica del ambiente", en

La Ley 1997-E, 1463 Responsabilidad Civil Doctrinas Esenciales Tomo V, 01/01/2007, 1497.

Martínez Alier, Joan (2009). El Ecologismo de los pobres. Barcelona, España. Editorial Icaria.

Medio ambiente y derechos humanos: justicia ambiental y el caso de Rinconada de Maipú. [en línea]https://www.fundacionhenrydunant. org/images/stories/biblioteca/Medio_Ambiente_Cambio_ Climatico_Derechos_Humanos_y_Desarrollo/Medio_Ambiente_y_ Derechos_Humanos_Justicia_Ambiental_caso_Rinconada_Maipu. pdf[consulta: 5 de julio de 2019].

morales lamberti, Alicia (2008). Gestación y remediación de Pasivos Ambientales. Alveroni, Córdoba, pág.6. págs.3-237.

Morales Lamberti, Alicia (2014). Evaluación de impacto ambiental y social: estándares sustantivos y de procedimiento en el Sistema Interamericano de derechos humanos. En cuaderno de derecho ambiental $\mathrm{N}^{\mathrm{o}}$ VI, págs. 71-110.

Morales Lamberti, Alicia (2015). "Los derechos humanos en el Código Civil y Comercial, como fuentes de integración hermenéutica y reconocimiento axiológico en la aplicación del derecho ambiental", en Revista de Derecho Ambiental $N^{\circ}$ 43, AbeledoPerrot, JunioSeptiembre 2015, págs. 139-164.

Morales Lamberti, Alicia. "Remediación de pasivos ambientales de la minería de uranio: Deuda ecológica y social". URL: 
http://revistas.bibdigital.ucc.edu.ar/ojs/index.php/RFD/article/ viewFile/735/587[consulta: 5 de julio de 2019].

Naciones Unidas: Asamblea General: Estudio analítico de la relación entre los derechos humanos y el medio ambiente. Informe de la Alta Comisionada de las Naciones Unidas para los Derechos Humanos, A/ HRC/19/34, 16 de diciembre de 2011.

Naciones Unidas: Asamblea General: Informe del Experto independiente sobre la cuestión de las obligaciones de derechos humanos relacionadas con el disfrute de un medio ambiente sin riesgos, limpio, saludable y sostenible, John H. Knox, A/HRC/22/43, 24 de diciembre de 2012. Nino, Carlos S (2012). Ética y derechos humanos, Astrea, Buenos Aires. Organización de los Estados Americanos, Comisión Interamericana de Derechos Humanos (2012), "Lineamientos para la elaboración de indicadores de progreso en materia de derechos económicos, sociales y culturales".

Rosillo Martínez, Alejandro (2016). "Repensar derechos humanos desde la liberación y la descolonialidad", Revista Direito e Práxis, Rio de Janeiro, Vol. 07, N. 13, págs. 721-749.

Saba, Roberto (2007). “(Des)igualdad estructural”. En R. Gargarella, \& M. Alegre , El Derecho a la Igualdad. Aportes para un constitucionalismo igualitario. Buenos Aires: Abeledo Perrot.

Sánchez Rubio, David (2005). "En torno a la reversión del Derecho y de los derechos humanos: mercado, biodiversidad, patrimonio común de la humanidad y especificidad indígena", CLACSO, pág. 2

Wazler, Michael (2015) Traducido por Heriberto Rubio. Las esferas de la justicia. Una defensa del pluralismo y la igualdad. Fondo de Cultura Económico, México.

Zaffaroni, Eugenio Raúl (2012). La Pachamama y el Humano. Buenos Aires, Ediciones Colihue.

Cómo citar el artículo: Doroni G, (2021). Costos ambientales-sociales en el marco de la mercantilización de los recursos naturales. Contextos de vulnerabilidad socialambiental. Derecho Global, Estudios sobre Derecho y Justicia, VI (17) pp. 77-106 https://DOI.org/10.32870/dgedj.v6i17.356 